\title{
Pharmacologic Identification of the Lower Esophageal Sphincter
}

\author{
James Christensen \\ From the Gastroenterology Research Laboratories, Department of Internal \\ Medicine, University of Iowa College of Medicine, Iowa City, Iowa 52240
}

A B S T R A C T The distal $2 / 3$ of the opossum esophagus contains only smooth muscle. Manometry shows that the most distal $1-2 \mathrm{~cm}$ is the lower esophageal sphincter. We used a variety of agonists to seek differences between circular muscle from the sphincteric segment and more rostral levels. Isometric contractions of strips from the distal $6 \mathrm{~cm}$ were recorded in vitro in response to acetylcholine, carbachol, methacholine, nicotine, DMPP, norepinephrine, norepinephrine with propranolol, barium, atropine, and potassium. Significant differences in threshold concentration occurred for all drugs except barium, atropine, and potassium, the more distal strips being more sensitive. The gradient of threshold was much steeper for norepinephrine than for the other drugs. Maximal responses did not differ among levels for the choline esters or ganglionic stimulants, but showed proximal diminution for norepinephrine. These differences in threshold concentration could represent differences in distribution density of drug receptor sites, differences in affinity of receptors for the agonists, differences in rates of uptake of agonists, or differences in rates of enzymatic hydrolysis; or they may have no common basis. The sphincter is defined, at least in part, in the esophageal wall rather than in the central nervous system. The greater magnitude of the difference in sensitivity to norepinephrine than for the other agents suggests that the adrenergic innervation is important in defining the lower esophageal sphincter.

\section{INTRODUCTION}

The body of the mammalian esophagus is normally relaxed, contracting on demand; the distal few centimeters of the esophagus are normally contracted, relaxing on demand. This reciprocity in the actions of the body and the distal segment is the basis for designating the latter the lower esophageal sphincter. In man the muscle of this sphincter and the segment of the esophagus rostral to it is all smooth muscle (1). A simple way

\footnotetext{
Dr. Christensen is a Markle Scholar in Academic Medicine. Received for publication 20 May 1969 and in revised form 7 November 1969.
}

to characterize smooth muscles is to observe drug responses of isolated muscle strips. A difference in the character of sphincteric and nonsphincteric smooth muscle might be either qualitative or quantitative. In such a study (2) in the cat esophagus, when three cholinergic drugs and norepinephrine were used, proximal segments were found to be less responsive to maximal drug doses than distal segments, but this did not relate to the lower esophageal sphincter, the lowest $2 \mathrm{~cm}$ in the cat (3). These quantitative differences were attributed to a preponderance of striated muscle in the proximal strips. In the cat, striated muscle may extend down to 3 or $4 \mathrm{~cm}$ above the stomach. The possibility that there is a difference defining the sphincter independent of the type of muscle making up the muscular wall can only be tested in animals in which both the sphincter and the suprasphincteric esophagus contain only smooth muscle. Aside from primates, the only animals with such an esophagus are some marsupials, including the opossum (4). The existence of a lower esophageal sphincter in this animal has not been previously demonstrated. The experiments described in this paper resemble, in part, those already reported in the cat (2). These experiments were intended to demonstrate the existence of the lower esophageal sphincter in the opossum and to discover differences between the smooth muscle from the lower esophageal sphincter and adjacent nonsphincteric smooth muscle.

\section{METHODS}

Manometric demonstration of the sphincter. We studied 10 adult male and female opossums (Didelphis virginiana) weighing $2.5-4.0 \mathrm{~kg}$. They were anesthetized with intraperitoneal sodium pentobarbital, $45 \mathrm{mg} / \mathrm{kg}$, and strapped supine to an animal board. Esophageal manometry was performed, as in man, with three polyethylene catheters, I.D. 0.055 inches, tied together, with distal lateral openings $2 \mathrm{~cm}$ apart. Each catheter was perfused with distilled water at $1.2 \mathrm{ml} / \mathrm{min}$, and led to a pressure transducer ${ }^{1}$ whose output was recorded on an ink-writing polygraph. ${ }^{*}$ The catheters were inserted perorally so that all distal openings lay within

\footnotetext{
${ }^{1}$ Statham pressure transducer model P23De.

${ }^{2}$ Beckman type RM Dynograph with coupler 9853.
} 
TABLE I

Mean Pressure Profiles through the Distal Esophageal Sphincter in 10 Opossums*

\begin{tabular}{|c|c|c|c|c|c|c|c|c|c|c|}
\hline \multirow{2}{*}{$\begin{array}{l}\text { Distance below } \\
\text { incisor teeth }\end{array}$} & \multicolumn{10}{|c|}{ Animal No. } \\
\hline & 1 & 2 & 3 & 4 & 5 & 6 & 7 & 8 & 9 & 10 \\
\hline $\mathrm{cm}$ & \multicolumn{10}{|c|}{ Mean pressure in $\mathrm{mm} \mathrm{Hg}$} \\
\hline 33.0 & & & & 6 & & & & 2 & 2 & 4 \\
\hline 32.5 & & & & 7 & & & & 2 & 2 & 2 \\
\hline 32.0 & & 7 & 4 & 7 & 4 & 7 & 6 & 2 & 2 & 4 \\
\hline 31.5 & & 8 & 3 & 3 & 3 & 4 & 6 & 5 & 2 & 3 \\
\hline 31.0 & 4 & 6 & 3 & 4 & 7 & 7 & 6 & 10 & 2 & 4 \\
\hline 30.5 & 6 & 7 & 3 & 5 & 5 & 4 & 6 & 4 & 22 & 4 \\
\hline 30.0 & 6 & 4 & 3 & 3 & 4 & 7 & 4 & 1 & 11 & 4 \\
\hline 29.5 & 5 & 3 & 5 & 3 & 3 & 4 & 4 & 1 & 2 & 4 \\
\hline 29.0 & 5 & 4 & 5 & 3 & 3 & 6 & 4 & 1 & 2 & 10 \\
\hline 28.5 & 5 & 4 & 15 & 4 & 3 & 5 & 4 & 1 & 0 & 26 \\
\hline 28.0 & 5 & 6 & 19 & 11 & 25 & 5 & 4 & -1 & 2 & 18 \\
\hline 27.5 & 5 & 22 & 6 & 27 & 18 & 5 & 4 & -1 & 1 & 5 \\
\hline 27.0 & 11 & 20 & 6 & 7 & 7 & 14 & 5 & -1 & 1 & 7 \\
\hline 26.5 & 15 & 3 & 4 & 3 & 3 & 8 & 16 & -1 & 1 & 6 \\
\hline 26.0 & 11 & $3 a$ & 3 & 2 & 6 & 10 & 2 & -1 & 1 & 6 \\
\hline 25.5 & 10 & 4 & 2 & 2 & 3 & 7 & 7 & -1 & 1 & -1 \\
\hline 25.0 & 8 & 3 & -1 & 3 & -1 & 7 & 5 & -1 & 1 & 0 \\
\hline 24.5 & 6 & 2 & -1 & 0 & -1 & 1 & 4 & -1 & -1 & -3 \\
\hline 24.0 & 6 & 2 & -1 & -1 & -3 & 2 & 3 & -1 & -1 & -3 \\
\hline 23.5 & 3 & 2 & -1 & -2 & -2 & 1 & 2 & 0 & -1 & -2 \\
\hline 23.0 & 2 & -2 & -1 & -1 & -2 & -1 & 0 & -1 & -1 & -2 \\
\hline 22.5 & 2 & -2 & -1 & -2 & -2 & -1 & -1 & -1 & -1 & -1 \\
\hline 22.0 & 0 & -2 & -2 & -3 & -1 & -1 & -1 & 0 & -1 & -2 \\
\hline 21.5 & -2 & -2 & -1 & -3 & -1 & -2 & 0 & -1 & 0 & -3 \\
\hline 21.0 & -2 & -2 & -1 & -3 & -3 & -1 & 0 & 0 & -1 & -2 \\
\hline $\begin{array}{l}20.5 \\
20.0\end{array}$ & $\begin{array}{l}-2 \\
-1\end{array}$ & $\begin{array}{l}-2 \\
-4\end{array}$ & $\begin{array}{r}0 \\
-1\end{array}$ & $\begin{array}{l}-2 \\
-2\end{array}$ & $\begin{array}{l}-2 \\
-2\end{array}$ & $\begin{array}{l}0 \\
0\end{array}$ & $\begin{array}{l}-2 \\
-2\end{array}$ & $\begin{array}{l}-1 \\
-1\end{array}$ & $\begin{array}{l}-1 \\
-1\end{array}$ & $\begin{array}{l}-2 \\
-2\end{array}$ \\
\hline 19.5 & -2 & -2 & -1 & -2 & -2 & 0 & 0 & 0 & -1 & -2 \\
\hline 19.0 & -2 & -2 & 0 & -1 & -3 & -1 & -2 & -1 & -1 & -2 \\
\hline
\end{tabular}

* Figures for each animal are mean pressures at each level calculated from two pullthrough procedures across the lower esophageal sphincter. Since three catheters were used, each number is the mean of six determinations.

the stomach. They were withdrawn in $\frac{1}{2} \mathrm{~cm}$ steps; we recorded for at least $1 \mathrm{~min}$ at each step. The animals often swallowed during this procedure. Each animal was studied twice; then it was killed by exsanguination and the stomach was exposed. The distance from the incisor teeth to the gastroesophageal junction was measured with another piece of polyethylene tubing inserted perorally and palpated through the wall of the esophagus.

Studies of the isolated muscle strips. We studied adult male and female opossums weighing $2.0-6.7 \mathrm{~kg}$. They were anesthetized with intraperitoneal sodium pentobarbital, 50 $\mathrm{mg} / \mathrm{kg}$, and the chest was opened. The heart was excised and the exposed esophagus measured and marked in situ. In these animals the phrenoesophageal ligament surrounds the esophagus where it traverses the diaphragm, 2-4 cm above the gastroesophageal junction. The striated muscle-smooth muscle junction was identified by inspection; striated muscle is orange-red, smooth muscle, pale pink. In all animals this junction was at least $6 \mathrm{~cm}$ above the phrenoesophageal ligament. The entire esophagus, including a cuff of proximal stomach, was removed and pinned flat in a dish of Krebs-
Ringer solution, bubbled with $95 \% \mathrm{O}_{2}-5 \% \mathrm{CO}_{2}$, at $37^{\circ}-38^{\circ} \mathrm{C}$. It was stretched to its length in situ and the mucosa was removed by sharp dissection at the level of the submucosa. The distal $6 \mathrm{~cm}$ of the remaining muscular wall was cut into transverse strips. Each strip was as long as the circumference of the esophagus and exactly $1 \mathrm{~cm}$ wide. The linear measurement of the esophagus, critically identifying the levels of the cuts defining the strips, was made from the gastroesophageal junction. This junction was identified by inspection as the place where the narrow esophagus flares into the stomach. Obviously, there was some variability in this determination, of the order of $3 \mathrm{~mm}$. Each strip was transferred to a $50 \mathrm{ml}$ organ bath filled with equilibrated Krebs-Ringer solution ${ }^{3}$ at $36.5^{\circ}-38.5^{\circ} \mathrm{C}$ and attached to a force-displacement transducer ${ }^{*}$ for isometric recording of

${ }^{3}$ The Krebs-Ringer solution had the following composition (mM) : $\mathrm{Na}^{+} 138.6, \mathrm{~K}^{+} 4.6, \mathrm{Ca}^{++} 2.5, \mathrm{Mg}^{++} 1.2, \mathrm{Cl}^{-} 126.2$, $\mathrm{HCO}_{3}-21.9, \mathrm{PO}_{4}=1.2$, glucose 49.6.

- Transducer model FT 0.03C, Grass Instrument Company, Quincy, Mass. 
tension changes in the circular muscle layer. Six identical bath-transducer assemblies accomodated all six strips so that the six strips from each animal could be studied simultaneously. The distribution of the six strips among the six baths was varied. The outputs of all six transducers were recorded at the same time on a six-channel curvilinear inkwriting polygraph. Each strip was weighed at the end of each experiment.

Responses were recorded to the following drugs added to the bath: acetylcholine bromide, methacholine chloride (acetylmethacholine chloride), carbachol (carbamylcholine chloride), nicotine sulfate, DMPP (1, 1-dimethyl-4-phenylpiperazinium iodide), $d$-l-norepinephrine hydrochloride, atropine sulfate, barium chloride, and potassium chloride. Responses to $d$ - $l$-norepinephrine hydrochloride were also recorded in the presence of propranolol hydrochloride. All drug concentrations are expressed as molar concentrations of the base; barium chloride and potassium chloride concentrations are expressed as molar concentrations of the salt.

In each experiment all six strips received exactly the same treatment simultaneously. Agonists were added, beginning with subthreshold concentrations, in progressively greater concentrations with thorough rinsing between doses.
Doses were increased logarithmically over a sufficient range to identify at least the first part of the dose-response curve for each level of the esophagus. The definition of the curve for most drugs was coarse because, within each decade of concentration, doses were made only at two points. The actual concentrations used are apparent from the illustrations showing dose-response curves. Threshold concentration for each agonist at each level was defined as the lowest concentration at which a response appeared.

Responses were recorded for a 5-7 min period after each drug addition. The onset of a response was easily distinguished, since these strips do not exhibit spontaneous activity. Responses were quantified by planimetry of the areas under the curves inscribed by the recording pens for a $2 \mathrm{~min}$ period after the first appreciable response to each dose of a drug. These responses, recorded in square centimeters, were converted to $\mathrm{g}-\mathrm{sec} / \mathrm{mg}$ of tissue by the following formula: [Area $\left(\mathrm{cm}^{2}\right) \times$ Tension $(\mathrm{g} / \mathrm{cm}) \div$ Paper Speed $(\mathrm{cm} / \mathrm{sec})] \div[$ Mass of strip $(\mathrm{mg})]=$ Response $(\mathrm{g}-$ $\mathrm{sec} / \mathrm{mg})$. To compare the magnitude of responses among strips, the assumption was made that strips from each level of the esophagus were potentially capable of yielding responses of equal magnitude, but that the magnitude of responses might vary among animals. Hence, responses were
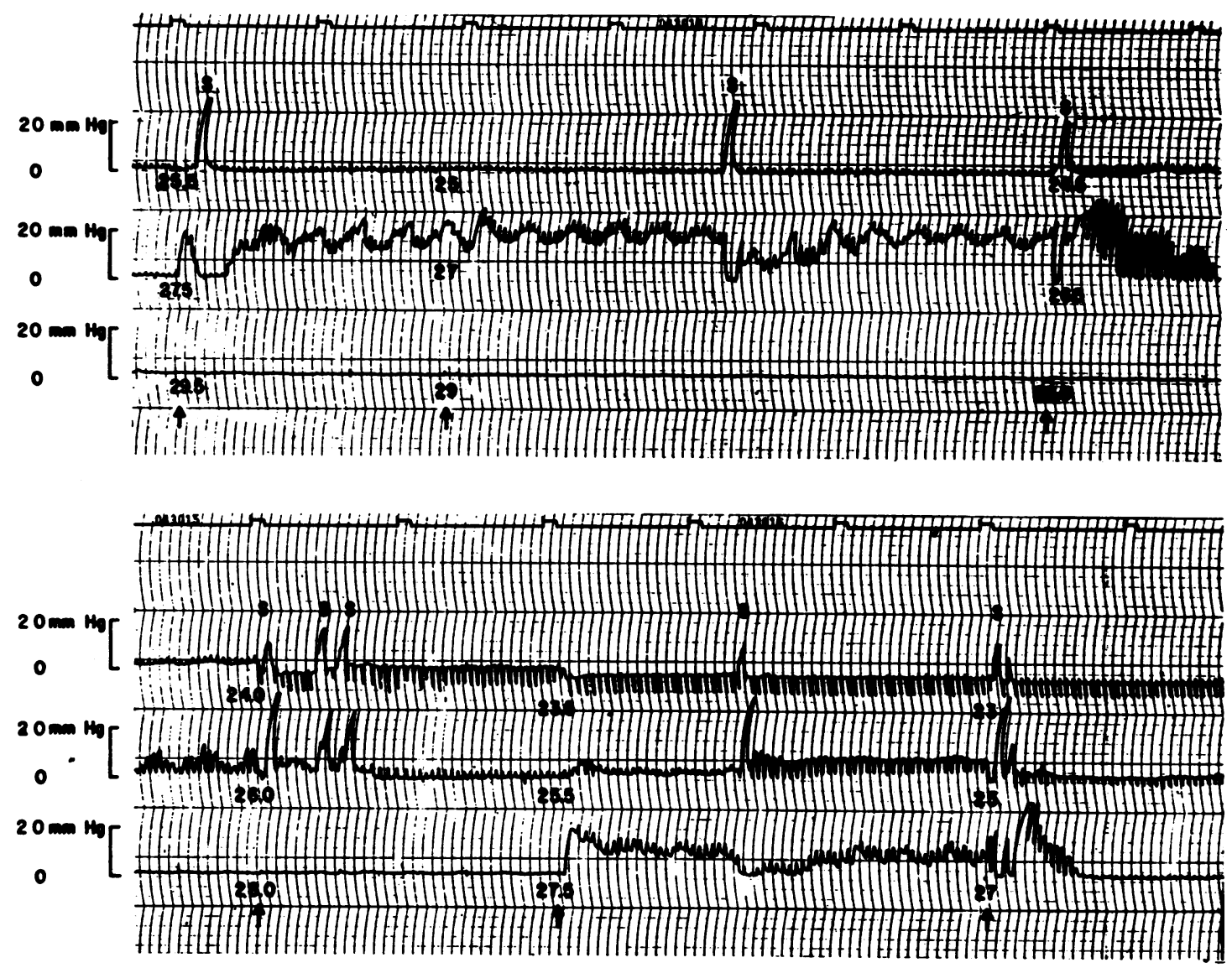

FIgURE 1 A record from intraluminal esophageal manometry in the opossum. Time, at the top, is marked in minutes. Arrows indicate successive steps in withdrawing the catheters. Numbers along the three traces indicate distance of the corresponding catheter opening below the incisor teeth. $S$ indicates an involuntary swallow. The two panels represent a continuous record. 
TABLE II

Distances to Gastroesophageal Junction, Lower Esophageal Sphincter, and Point of Inversion of Respiratory Pressures in 10 Opossums

\begin{tabular}{lrrrrrrrrrr}
\hline & \multicolumn{10}{c}{ Animal No. } \\
\cline { 2 - 10 } & 1 & 2 & 3 & 4 & 5 & 6 & 7 & 8 & 9 & 10 \\
\hline $\begin{array}{c}\text { Measured distance from teeth to } \\
\text { gastroesophageal junction, } c m\end{array}$ & 27.0 & 28.5 & 29.0 & 30.5 & 32.0 & 28.5 & 26.5 & 32.3 & 32.3 & 29.3 \\
$\begin{array}{c}\text { Distance from teeth to level of } \\
\text { highest mean pressure, } c m\end{array}$ & 26.5 & 27.5 & 28.0 & 27.5 & 28.0 & 27.0 & 26.0 & 31.0 & 30.5 & 28.5 \\
$\begin{array}{c}\text { Distance from teeth to level } \\
\text { of point of inversion of } \\
\text { respiratory pressures, } c m\end{array}$ & 24.5 & 24.5 & 26.0 & 25.5 & 24.5 & 25.0 & 22.5 & 29.0 & 26.0 & 26.0 \\
\hline
\end{tabular}

normalized by considering the greatest single response achieved by any strip in each animal as $100 \%$ and computing all responses of all the strips from that animal as per. cent of this maximum.

The numbers of animals studied with each drug were: acetylcholine 4, carbachol 3 , methacholine 3 , nicotine 3 , DMPP 3, norepinephrine 4, norepinephrine with propranolol 4 , atropine 3 , barium chloride 3 , and potassium chloride 3 . 33 animals were studied in all, a total of 198 strips. Each esophagus received only one agonist.

Differences in threshold concentration among strips, for all 10 treatments, were compared statistically by an analy- sis of slope of threshold concentrations among the six levels of the esophagus.

\section{RESULTS}

Manometry. In all 10 animals both upper and lower esophageal sphincters were demonstrated. Mean intragastric pressure was $2-8 \mathrm{~mm} \mathrm{Hg}$ above ambient pressure, with slight positive deflections with inspiration. The lower sphincter was identified as a zone of resting pressure up to $50 \mathrm{~mm} \mathrm{Hg}$ above mean intragastric pres-

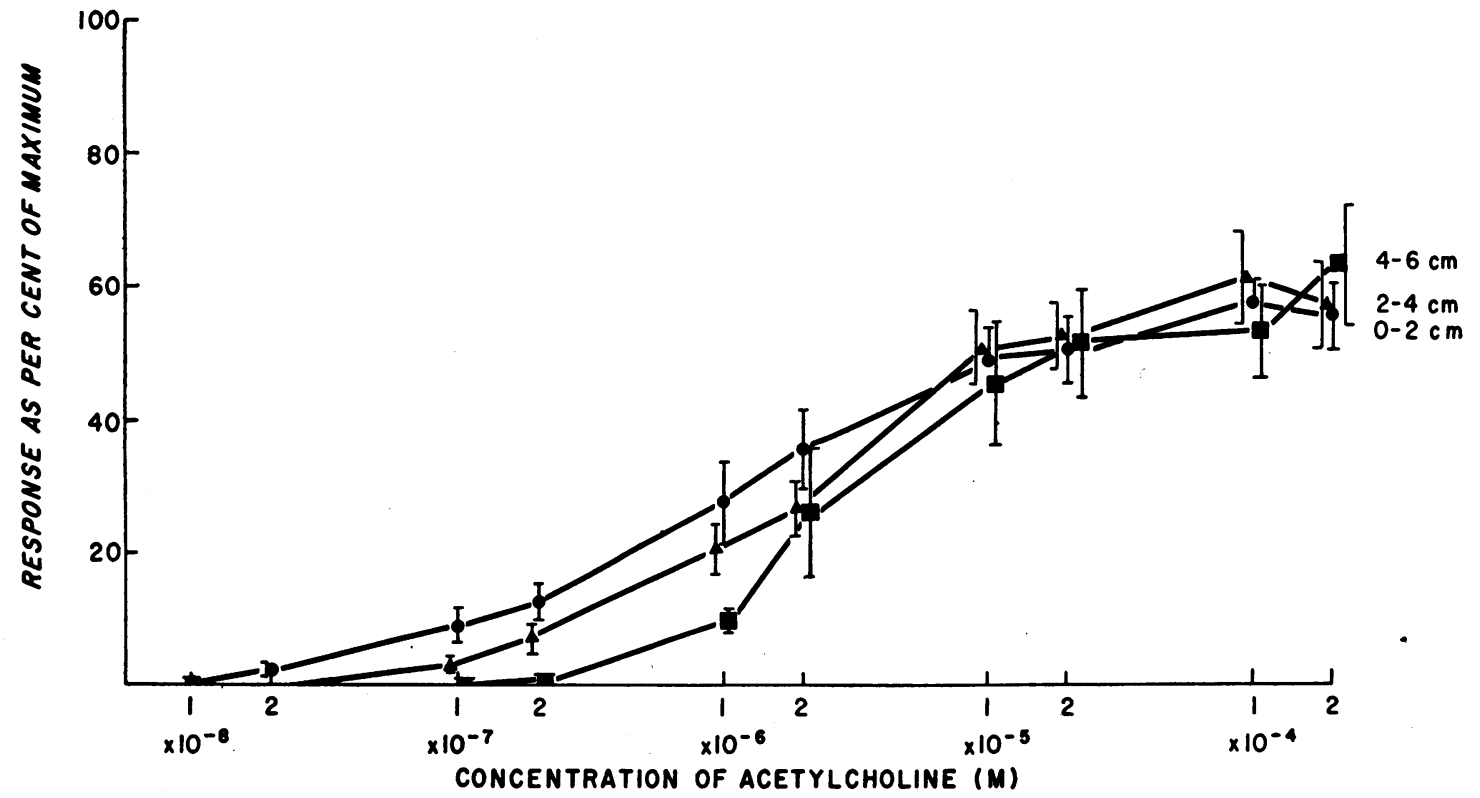

FIgURE 2 Comparison of dose-response curves of three adjacent segments of the distal opossum esophagus to acetylcholine. Each curve represents two adjacent strips: solid circles indicate responses of the strips at $0-1$ and $1-2 \mathrm{~cm}$ above the stomach; solid triangles indicate strips at 2-3 and 3-4 cm above the stomach; solid squares indicate strips at 4-5 and 5-6 cm. Points on the curves are offset slightly for clarity. The horizontal axis shows molar concentration of acetylcholine (log scale); the vertical axis shows response as per cent of the largest response observed for any single strip in each experiment. Brackets indicate one standard error. Curves represent four experiments so that each curve is the mean of eight strips. 


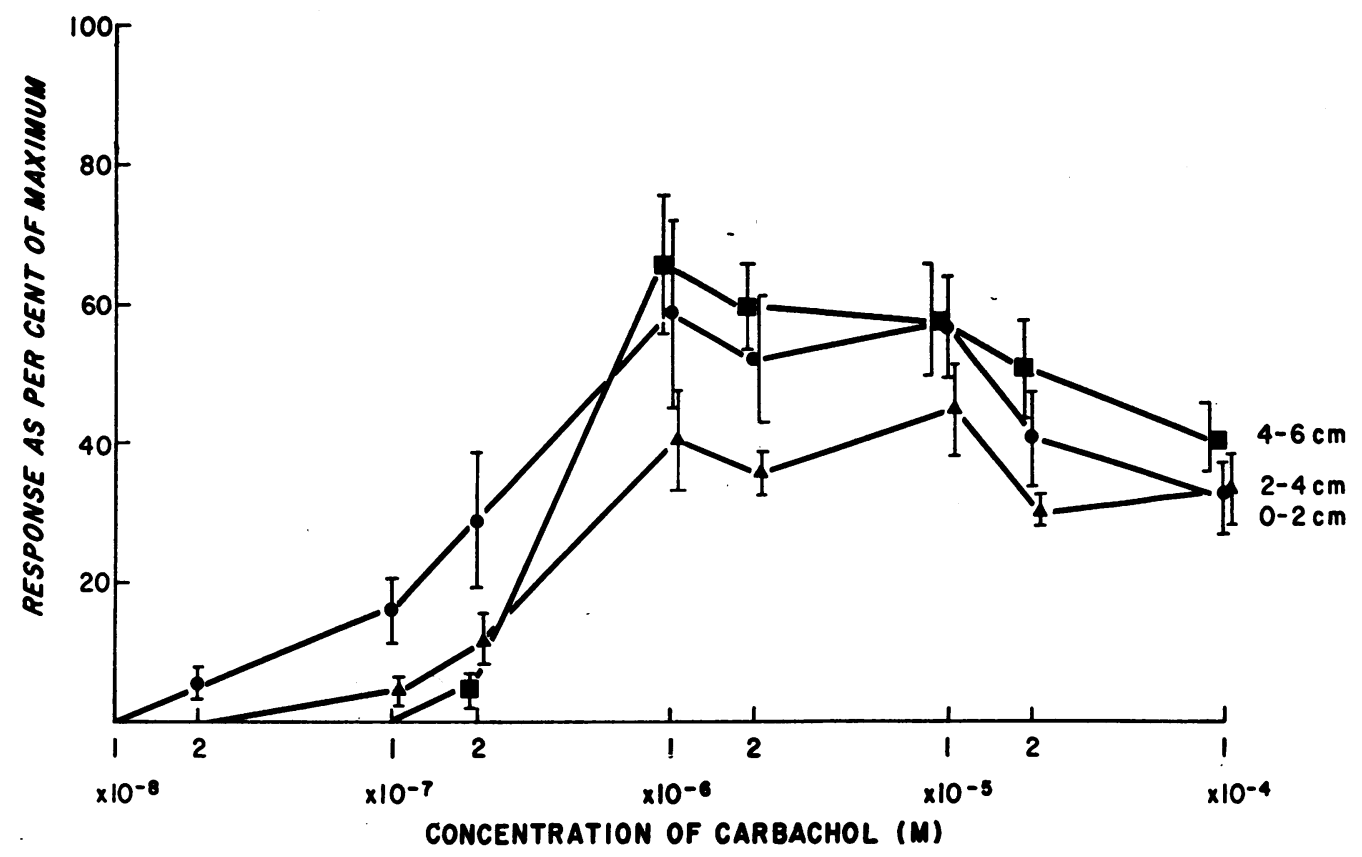

Figure 3 Comparison of dose-response curves of three adjacent segments of the distal opossum esophagus to carbachol. Symbols and axes are the same as in Fig. 2. Curves represent three experiments so that each curve is the mean of six strips.

sure. Mean values appear in Table I. The distance below the incisors to this high pressure zone corresponded sured post mortem. The length of this high pressure to the level of the gastroesophageal junction as meazone was apparently no more than $2 \mathrm{~cm}$; it was never found at more than four stops during the pullout. Im-

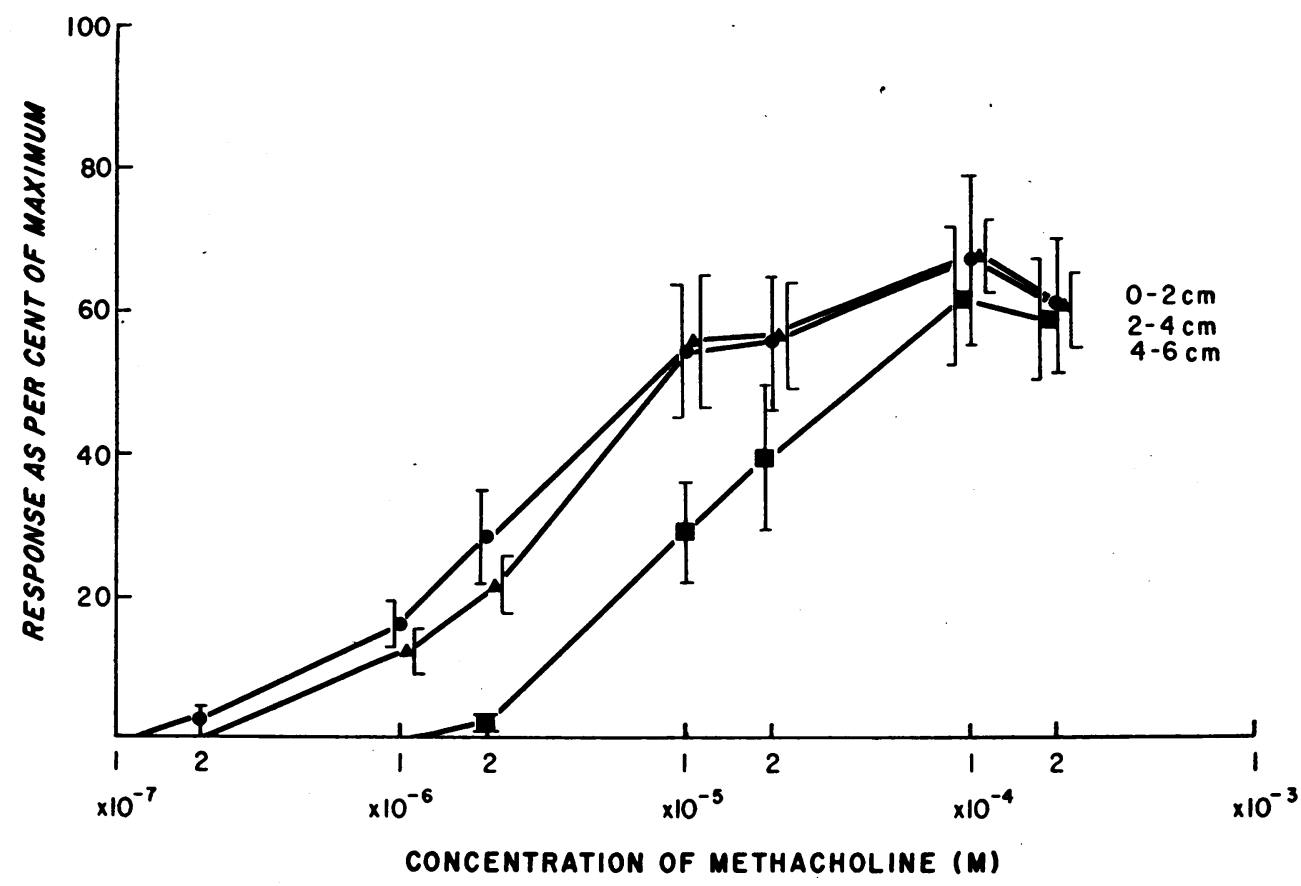

FIGURE 4 Comparison of dose-response curves of three adjacent segments of the distal opossum esophagus to methacholine. Symbols and axes are the same as in Fig. 2. Curves represent three experiments so that each curve is the mean of six strips. 
mediately proximal to the lower sphincter mean resting pressure was $2-8 \mathrm{~mm} \mathrm{Hg}$ above ambient pressure with positive deflections on inspiration. At a variable distance above the distal high pressure zone respiratory fluctuations reversed and mean resting pressure became 1-4 $\mathrm{mm} \mathrm{Hg}$ below ambient pressure; this pattern was found at all proximal levels until another region of resting pressure above ambient pressure was encountered proximally. The level of this zone corresponded in all animals to the level of the pharyngoesophageal junction as measured post mortem. Involun- tary swallowing occurred during the procedure. During such swallows resting pressure in both distal and proximal high-pressure zones fell; in the segment of esophagus between high-pressure zones there was a brief pressure peak which was propagated distally. Fig. 1 is a representative tracing of the pressure profile of the lower esophageal sphincter. Table I gives calculated data from all 20 experiments. The point of inversion of respiratory pressures was $2-4 \mathrm{~cm}$ proximal to the midpoint of the sphincter in all animals (Table II). Small errors appear in these measurements of distance from

TABle III

Threshold Concentrations for Agonists at Six Adjacent Levels of the Esophagus*

\begin{tabular}{|c|c|c|c|c|c|c|c|c|c|c|c|}
\hline Drugs & $\begin{array}{l}\text { Exp. } \\
\text { No. }\end{array}$ & $\begin{array}{l}0-1 \\
\mathrm{~cm}\end{array}$ & $\begin{array}{l}1-2 \\
\mathrm{~cm}\end{array}$ & $\begin{array}{l}2-3 \\
\mathrm{~cm}\end{array}$ & $\begin{array}{l}3-4 \\
\mathrm{~cm}\end{array}$ & $\begin{array}{l}4-5 \\
\mathrm{~cm}\end{array}$ & $\begin{array}{l}5-6 \\
\mathrm{~cm}\end{array}$ & Slope & $\begin{array}{l}\text { Mean } \\
\text { slope }\end{array}$ & $t$ & $P$ \\
\hline \multirow[t]{4}{*}{ Acetylcholine } & 1 & 2.0000 & 1.3010 & 2.0000 & 2.0000 & 2.0000 & 2.3010 & 0.1209 & 0.2128 & 2.7212 & $<0.01$ \\
\hline & 2 & 2.0000 & 2.0000 & 2.0000 & 2.0000 & 2.3010 & 2.3010 & 0.0688 & & & \\
\hline & 3 & 2.0000 & 2.0000 & 2.3010 & 3.0000 & 3.0000 & 3.0000 & 0.2485 & & & \\
\hline & 4 & 1.0000 & 1.3010 & 2.0000 & 2.0000 & 3.0000 & 3.0000 & 0.4313 & & & \\
\hline \multirow[t]{3}{*}{ Carbachol } & 1 & 1.3010 & 1.3010 & 2.0000 & 2.3010 & 3.0000 & 3.0000 & 0.3969 & 0.2903 & 3.2148 & $<0.005$ \\
\hline & 2 & 1.3010 & 1.3010 & 2.0000 & 2.3010 & 2.3010 & 2.3010 & 0.2371 & & & \\
\hline & 3 & 1.3010 & 2.0000 & 2.0000 & 2.3010 & 3.0000 & 2.3010 & 0.2371 & & & \\
\hline \multirow[t]{3}{*}{ Methacholine } & 1 & 2.3010 & 3.0000 & 3.0000 & 3.3010 & 3.3010 & 3.3010 & 0.1772 & 0.1972 & 2.1838 & $<0.025$ \\
\hline & 2 & 3.0000 & 3.0000 & 3.0000 & 3.3010 & 4.0000 & 3.3010 & 0.1373 & & & \\
\hline & 3 & 2.3010 & 3.0000 & 3.0000 & 3.3010 & 3.3010 & 4.0000 & 0.2771 & & & \\
\hline \multirow[t]{3}{*}{ Nicotine } & 1 & 4.0000 & 5.0000 & 5.3010 & 5.3010 & 6.0000 & 6.0000 & 0.3714 & 0.3391 & 3.8804 & $<0.001$ \\
\hline & 2 & 5.3010 & 6.0000 & 6.0000 & 6.3010 & 6.3010 & 6.3010 & 0.1772 & & & \\
\hline & 3 & 4.0000 & 5.0000 & 5.3010 & 6.3010 & 6.3010 & 6.3010 & 0.4688 & & & \\
\hline \multirow[t]{3}{*}{ DMPP } & 1 & 4.6990 & 5.0000 & 4.6990 & 5.0000 & 5.6990 & 5.6990 & 0.2113 & 0.3504 & 3.7552 & $<0.0025$ \\
\hline & 2 & 3.6990 & 4.0000 & 4.6990 & 3.6990 & 5.6990 & 5.6990 & 0.4599 & & & \\
\hline & 3 & 3.6990 & 4.6990 & 4.6990 & 5.0000 & 5.6990 & 5.6990 & 0.3800 & & & \\
\hline \multirow[t]{4}{*}{ Norepinephrine } & 1 & 4.0000 & 4.3010 & 6.0000 & 6.3010 & 7.0000 & 7.0000 & 0.6685 & 0.4628 & 5.9182 & $<0.0005$ \\
\hline & 2 & 4.0000 & 4.3010 & 4.3010 & 5.0000 & 5.0000 & 5.0000 & 0.2227 & & & \\
\hline & 3 & 3.3010 & 4.0000 & 4.3010 & 5.3010 & 5.3010 & 6.0000 & 0.5256 & & & \\
\hline & 4 & 4.0000 & 4.0000 & 4.0000 & 5.3010 & 5.3010 & 6.0000 & 0.4344 & & & \\
\hline \multirow{4}{*}{$\begin{array}{l}\text { Norepinephrine with } \\
\text { propranolol }\end{array}$} & 1 & 1.0000 & 1.0000 & 2.0000 & 1.3010 & 2.0000 & 3.3010 & 0.3944 & 0.7014 & 8.9694 & $<0.0005$ \\
\hline & 2 & 1.0000 & 2.0000 & 2.0000 & 5.3010 & 5.3010 & 5.0000 & 0.9486 & & & \\
\hline & 3 & 1.0000 & 2.0000 & 2.3010 & 4.0000 & 4.0000 & 4.0000 & 0.6485 & & & \\
\hline & 4 & 1.0000 & 1.3010 & 2.3010 & 3.3010 & 3.3010 & 5.3010 & 0.8144 & & & \\
\hline \multirow[t]{3}{*}{ Barium } & 1 & 5.7619 & 6.0607 & 5.7619 & 6.0607 & 6.7619 & 6.7619 & 0.2113 & 0.1189 & 1.3167 & $>0.05$ \\
\hline & 2 & 6.0607 & 5.7619 & 6.7619 & 6.7619 & 5.7619 & 6.0607 & 0.0000 & & & \\
\hline & 3 & 6.7619 & 5.7619 & 6.0607 & 6.7619 & 6.0607 & 6.7619 & 0.1456 & & & \\
\hline \multirow[t]{3}{*}{ Atropine } & 1 & 4.7782 & 4.7782 & 4.9031 & 5.3010 & 5.3010 & 5.3010 & 0.1208 & 0.1538 & 1.7032 & $>0.05$ \\
\hline & 2 & 4.0000 & 4.0000 & 4.0000 & 4.7782 & 4.9031 & 4.9031 & 0.2286 & & & \\
\hline & 3 & 4.3010 & 4.6021 & 4.4771 & 4.6021 & 4.8451 & 4.8451 & 0.1021 & & & \\
\hline \multirow[t]{3}{*}{ Potassium } & 1 & 7.2900 & 7.2900 & 7.2900 & 7.2900 & 7.2900 & 7.2900 & 0.0000 & 0.0061 & 0.0675 & $>0.05$ \\
\hline & 2 & 7.2900 & 7.2900 & 7.2900 & 7.2900 & 7.2900 & 7.2900 & 0.0000 & & & \\
\hline & 3 & 7.1614 & 7.1614 & 7.2900 & 7.2900 & 7.1614 & 7.2900 & 0.0183 & & & \\
\hline
\end{tabular}

* Threshold concentrations are expressed as log of namomolar concentrations. 


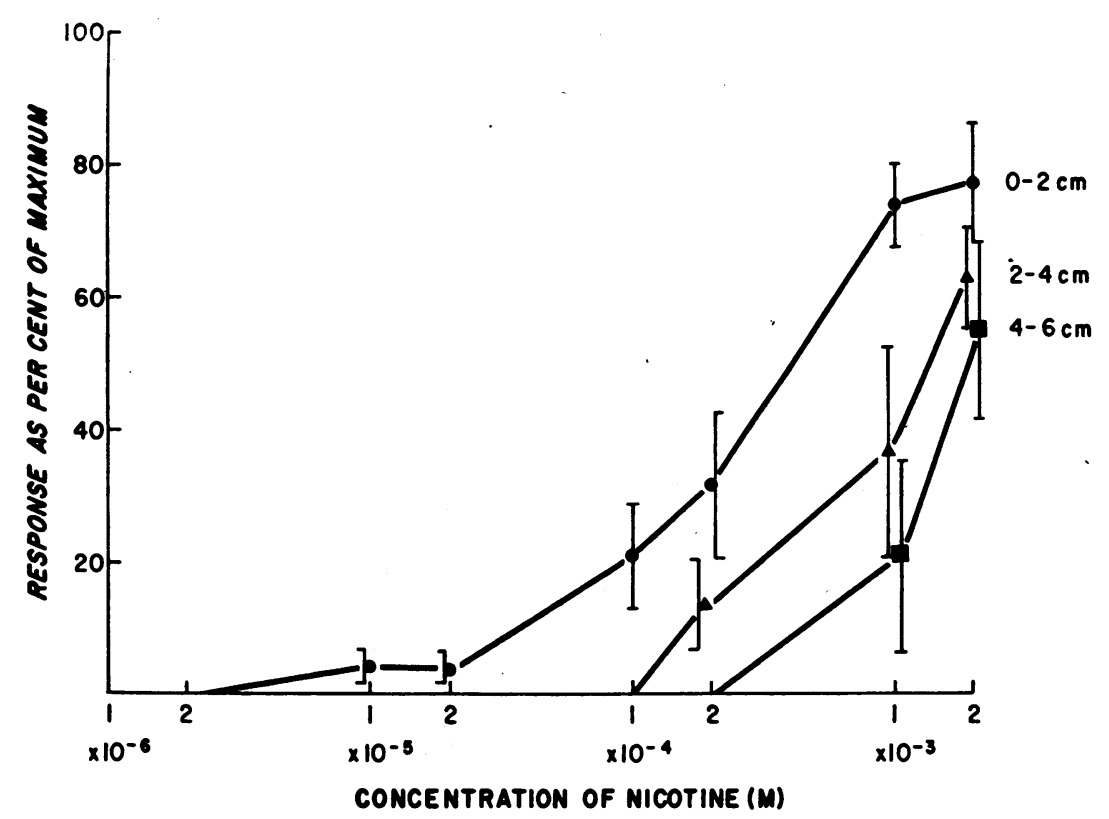

FIGURE 5 Comparison of dose-response curves of three adjacent segments of distal opossum esophagus to nicotine. Symbols and axes are the same as in Fig. 2. Curves represent three experiments so that each curve is the mean of six strips.

the teeth because the luminal catheters are not fixed in relation to the surrounding esophagus.

Responses of strips to acetylcholine, carbachol, and methacholine. The three cholinergic drugs all caused contractions which were qualitatively similar at all levels. The only difference among levels was in thresh- old concentrations. In all esophagi studied, for all three drugs, the lowest strips responded to lower concentrations than higher strips. Maximum tension achieved by strips from upper levels did not differ from maximum tension for the lower strips. The dose-response curves for the strips for acetylcholine appear in Fig. 2,

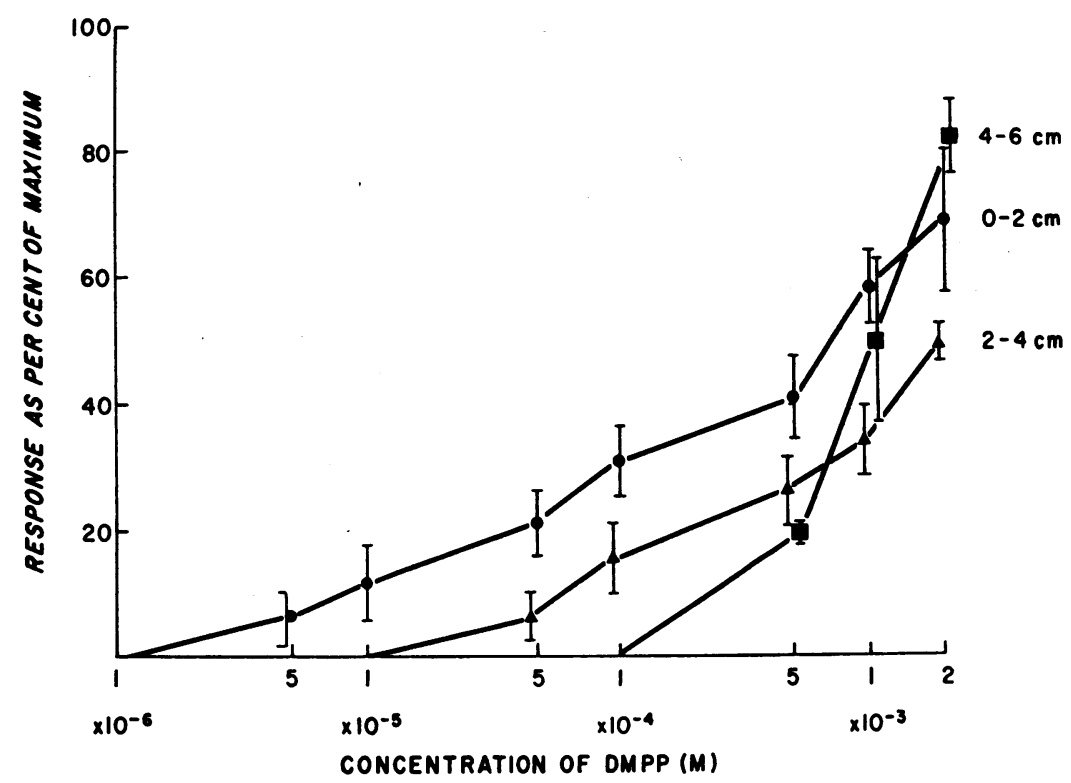

FIGURE 6 Comparison of dose-response curves of three adjacent segments of distal opossum esophagus to DMPP. Symbols and axes are the same as in Fig. 2. Curves represent three experiments so that each curve is the mean of six strips. 


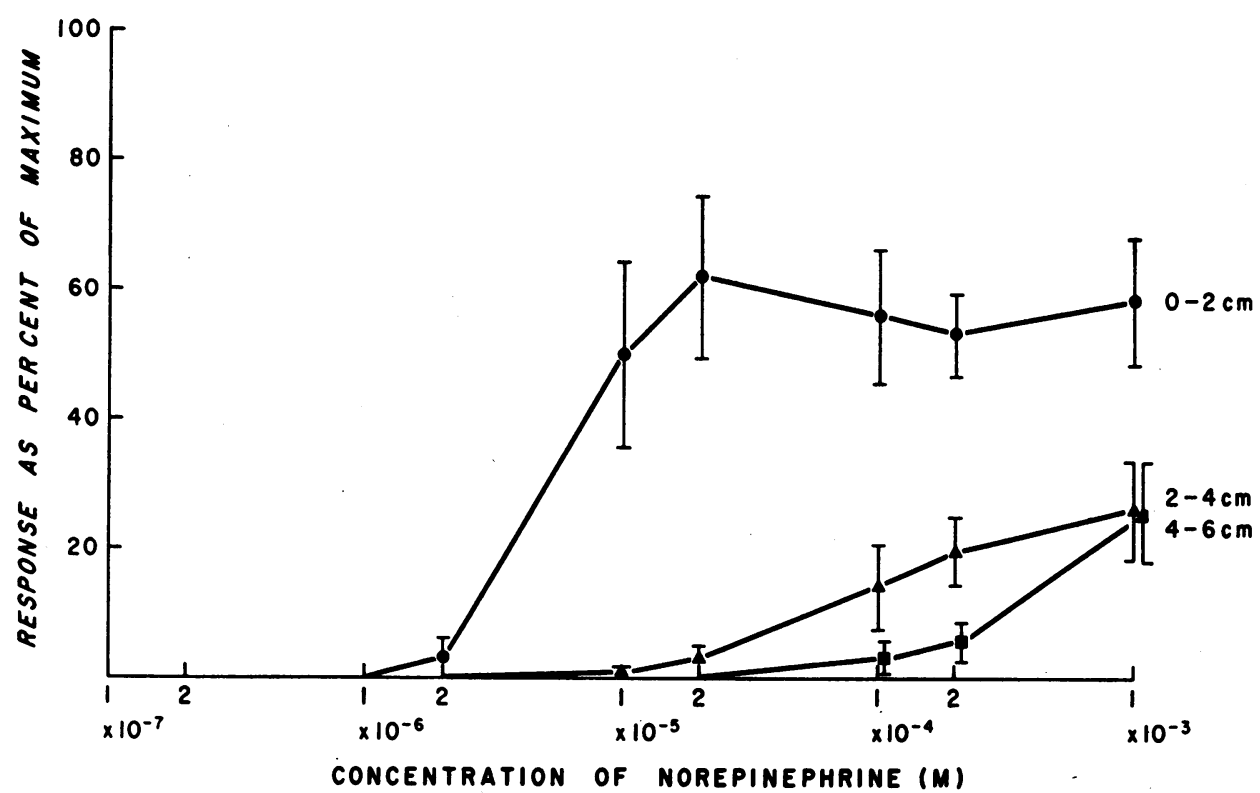

Figure 7 Comparison of dose-response curves of three adjacent segments of the opossum esophagus to norepinephrine. Symbols and axes are the same as in Fig. 2. Curves represent four experiments so that each curve is the mean of eight strips.

for carbachol in Fig. 3, and for methacholine in Fig. 4. Each figure represents three dose-response curves: one for the lowest two strips, one for the intermediate two strips, and one for the highest two strips. Threshold concentrations for the three drugs at all six levels

of the esophagus are presented in Table III. The slopes of the regression lines for threshold concentrations among the six levels are significantly different from zero for all three drugs (Table III).

Responses to nicotine and DMPP. The ganglionic

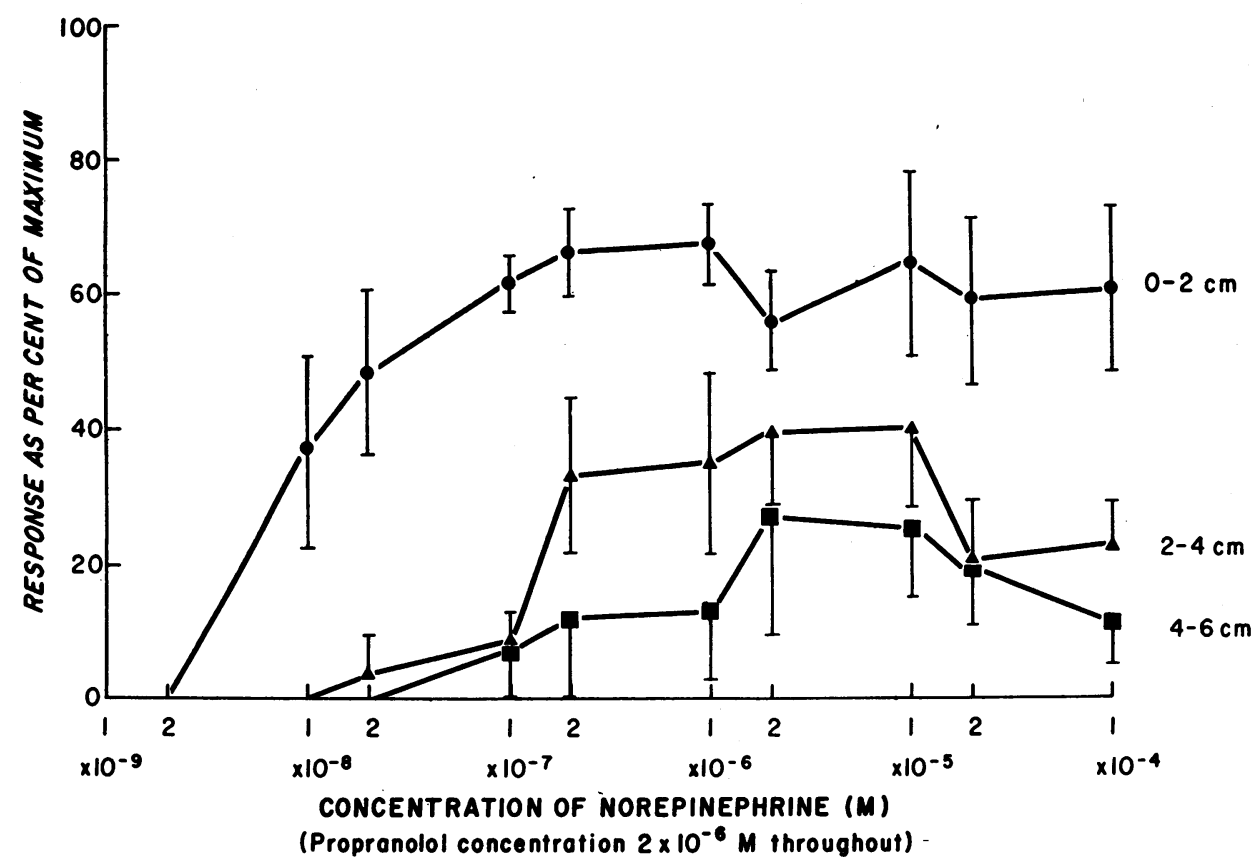

FIGURE 8 Comparison of dose-response curves of three adjacent segments of distal opossum esophagus to norepinephrine with propranolol. Symbols and axes are the same as in Fig. 2. Curves represent four experiments so that each curve is the mean of eight strips. 


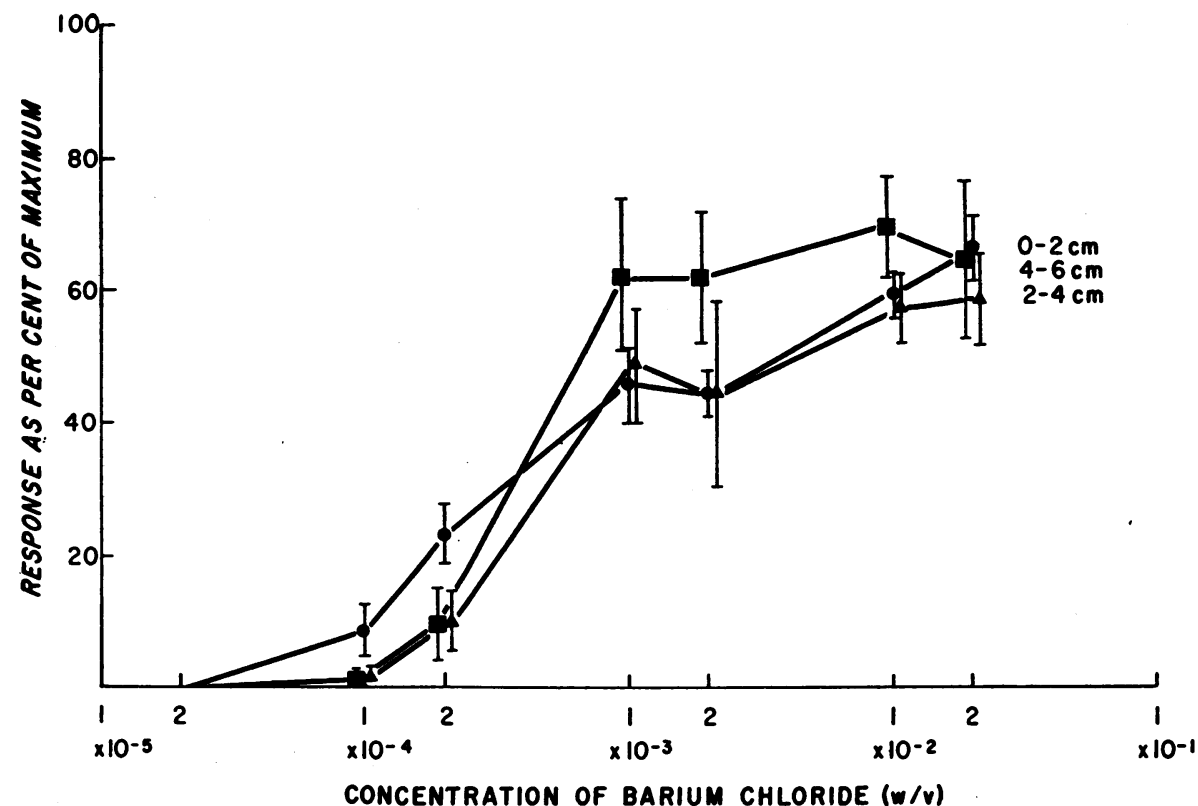

FIGURE 9 Comparison of dose-response curves of three adjacent segments of distal opossum esophagus to barium chloride. Symbols and axes are the same as in Fig. 2. Curves represent three experiments so that each curve is the mean of six strips.

stimulants, nicotine and DMPP, both caused contractions which were qualitatively similar at all levels. Threshold concentrations were less at lower levels, but maximal responses were similar among levels. Doseresponse curves for these two drugs are shown in Figs. 5 and 6 , in which curves for the six levels are combined into 3 curves, each representing two adjacent strips. Threshold concentrations for the three drugs at all six levels of the esophagus are shown in Table III. The slopes of the regression lines for threshold concentrations among the six levels are significantly different from zero (Table III).

Responses to norepinephrine. Norepinephrine, both alone and with propranolol, $2 \times 10^{-6} \mathrm{~mole} / \mathrm{liter}$, caused contractions, as it does in esophageal muscle from other species (5-7). Responses were not qualitatively different among levels but both threshold concentrations and maximal responses were very different among levels. Higher levels of the esophagus had larger threshold concentrations and lesser maximal responses than lower levels. Propranolol increased the sensitivity of all levels to norepinephrine, suggesting that this response is mediated by adrenergic $\alpha$-receptors, as is the case in other species (5-7). Dose-response curves for norepinephrine alone and with propranolol appear in Figs. 7 and 8, respectively. Threshold concentrations for norepinephrine, alone and with propranolol, are shown in Table III. The slopes of the regression lines for norepinephrine threshold concentrations among the six levels, in both conditions, are significantly different from zero (Table III).

Responses to barium chloride, potassium chloride, and atropine. The effect of barium was identical among the six levels of the esophagus. The dose-response curves appear not to be different (Fig. 9). The slope of the threshold concentrations was not significantly different from zero (Table III).

Atropine sulfate, in large concentrations, excites this tissue. The dose-response curve for upper levels of the opossum esophagus has already been published (8). When six levels of the esophagus were compared in terms of threshold to atropine, small differences appeared. The slope of the regression line for this difference in threshold among levels is not significantly different from zero (Table III).

Potassium chloride caused contractions at all six levels of the esophagus. The slope of the regression line of threshold concentrations is not significantly different from zero (Table III).

\section{DISCUSSION}

These experiments show a difference in threshold concentrations between various levels of the distal esophagus to a variety of exciting drugs. We previously sought such differences in the cat esophagus where we found a difference in magnitude of maximal response (2). In those experiments increments of drug concentration were probably too gross to show differences 
in threshold concentration if they exist. In the cat esophagus the difference in magnitude of maximal response was attributed to the predominance of striated muscle at more proximal levels of the esophagus. In the opossum all strips came from a level well below the striated muscle part of the esophagus. Hence the differences observed in the opossum esophagus must be attributed to different characteristics of the smooth muscle in this region.

The most obvious functional correlate for the observed gradients in drug sensitivity is the correlation of higher sensitivity with sphincteric muscle. The fact that the sensitivity to agonists was not found to break sharply at the point between the lowest and intermediate pairs of strips is due probably to variation in measurement of the levels of the cuts; it possibly also indicates that the differences which define the sphincter are graded over some short distance.

The quantitative differences found were demonstrable only for those agents which are believed either to be neurohumoral transmitters or to act in the same way as neurohumoral agents. Barium is, at least in part, a direct stimulant of gastrointestinal smooth muscle; this appears to be its chief mode of action in cat esophageal smooth muscle (9). The excitatory effect of very large concentrations of atropine on opossum esophageal smooth muscle appears also to be a direct effect (8). Potassium chloride is also a direct excitant of smooth muscle. The drugs which are, or act like, neurohumoral agents act on receptors, theoretical sites with selective affinity for these agents or their congeners. The differences in threshold concentrations for the cholinergic agents and ganglionic stimulants are most easily interpreted as indicating a difference in concentration of such receptors between the sphincteric and nonsphincteric muscle. These receptors are believed to be located either in the smooth muscle or in the intrinsic nerves of the esophageal wall or both.

Studies of the intrinsic nerves along the esophagus have not been done in the opossum. According to Irwin's studies in other mammals (10), cells of Auerbach's plexus are sparse rostrally but show a progressive increase caudally to achieve maximum density at the rostral end of the distal third of the esophagus. They diminish progressively below that point and are virtually absent at $1 / 2 \mathrm{~cm}$ above the gastroesophageal junction. Irwin did not specify what variations exist among the species he studied; this description may not be appropriate to the opossum or man at all.

The threshold concentration gradient for norepinephrine among the distal $6 \mathrm{~cm}$ of this esophagus is very much greater than the gradient for the choline esters or ganglionic stimulants. This evidence also is most easily interpreted as indicating a steep gradient in density of adrenergic $\alpha$-receptors. This suggests that the adrenergic innervation may be of greater significance in defining the lower esophageal sphincter. Anatomic studies of the adrenergic nerves of this part of the esophagus have not been reported.

A second explanation for the difference in sensitivity along the distal esophagus is that drug receptors, while distributed uniformly along the esophagus, have a gradient in their affinity for agonists. If the gradient is one of receptor affinity rather than receptor density, it is difficult to understand why it applies both to cholinergic and adrenergic receptors. A third possibility is that the differences in sensitivity represent differences in the rate of uptake of agonists into local sites of storage: in more densely innervated tissues the local nerves take up added agonist better than in less densely innervated tissues, leaving less agonist available to receptor sites. A fourth explanation, a possible gradient in cholinesterase concentration, seems unlikely in view of the fact that the gradient exists for methacholine, an agent which is less susceptible to enzymatic destruction than acetylcholine. It may be that these gradients have no common basis, that the gradients exist for different reasons. A rational explanation for these gradients requires much more information about the neuroanatomy and pharmacology of this tissue.

Whatever the reason for these gradients it appears that the smooth muscle making up the lower esophageal sphincter is, in itself, quantitatively different from that of the adjacent nonsphincteric smooth muscle. The sphincter is defined, at least in part, by differences within the wall of the esophagus rather than in the central nervous system. Since the gradient of threshold concentrations for norepinephrine is much steeper than those for the choline esters and ganglionic stimulants, it seems likely that the adrenergic innervation is the more important determinant of the sphincteric function of the distal few centimeters of the esophagus.

\section{ACKNOWLEDGMENTS}

The author acknowledges the technical assistance of $\mathrm{Mr}$. J. M. McCord and Mr. J. R. Warner. Propranolol was supplied through the courtesy of Dr. A. Sahagian-Edwards of Ayerst Laboratories.

This work was supported by Research Grant AM 11242, Training Grant AM-5390, and Research Career Development Award AM-20547 from the National Institute of Arthritis and Metabolic Diseases.

\section{REFERENCES}

1. Arey, L. B., and M. J. Tremaine. 1933. The muscle content of the lower oesophagus of man. Anat. Rec. 56: 315.

2. Christensen, J., and R. F. Dons. 1968. Regional variations in response of cat esophageal muscle to stimulation with drugs. J. Pharmacol. Exp. Ther. 161: 55. 
3. Clark, C. G., and J. R. Vane. 1961. The cardiac sphincter in the cat. Gut. 2: 252.

4. Christensen, J., and G. F. Lund. 1969. Esophageal responses to distension and electrical stimulation. J. Clin. Invest. 48 : 408.

5. Christensen, J., and E. E. Daniel. 1966. Electric and motor effects of autonomic drugs on longitudinal esophageal smooth muscle. Amer. J. Physiol. 211: 387.

6. Christensen, J., and E. E. Daniel. 1966. Effects of some autonomic drugs on circular esophageal smooth muscle. J. Pharmacol. Exp. Ther. 159: 243.
7. Bailey, D. M. 1965. The action of sympathomimetic amines on circular and longitudinal smooth muscle from the isolated oesophagus of the guinea pig. J. Pharm. Pharmacol. 17: 782.

8. Christensen, J., and G. F. Lund. 1968. Atropine excitation of esophageal smooth muscle. J. Pharmacol. Exp. Ther. 163 : 287.

9. Christensen, J. 1968. Barium stimulation of esophageal smooth muscle. Proc. Soc. Exp. Biol. Med. 128: 109.

10. Irwin, D. A. 1931. The anatomy of auerbach's plexus. Amer. J. Anat. 49: 141. 